\title{
Rhizomelic Chondrodysplasia Punctata
}

National Cancer Institute

\section{Source}

National Cancer Institute. Rhizomelic Chondrodysplasia Punctata. NCI Thesaurus. Code C85047.

An autosomal recessive inherited peroxisomal disorder caused by mutations in the PEX7, DHAPAT, and AGP genes. It is characterized by short limbs, bones and cartilage abnormalities, congenital cataracts, and severe mental retardation. 